\title{
High-Arctic nesting geese occupying less favourable nest sites are more vulnerable to predation
}

\author{
Helen B. Anderson ${ }^{1 *}$, Eva Fuglei ${ }^{2}$, Jesper Madsen ${ }^{3}$ \& René van der Wal ${ }^{1}$ \\ ${ }^{1}$ School of Biological Sciences, University of Aberdeen, Aberdeen, Scotland, UK; \\ ${ }^{2}$ Norwegian Polar Institute, Fram Centre, Tromsø, Norway; \\ ${ }^{3}$ Department of Bioscience, Aarhus University, Rønde, Denmark
}

\begin{abstract}
In a simple, rodent-free Arctic ecosystem in Svalbard, we assessed the nestsite characteristics of the main (and highly abundant) migratory herbivorepink-footed geese (Anser brachyrhynchus) - to determine which nesting geese were preferentially attacked and killed by the only local predator of adult geese, the Arctic fox (Vulpes lagopus). We collected data on goose carcasses and nest-site characteristics at one of the main pink-footed goose breeding areas in Svalbard. Arctic foxes depredated adult pink-footed geese from just over a quarter of the unsuccessful nests in the colony and carcasses were generally found just under $10 \mathrm{~m}$ away from a nest. Geese that occupied nests of poorer quality (limited visibility, further distance to forage patches and situated on flatter slopes) and were less well established (indicated by the low degree of fertilization from accumulations of goose droppings) were more likely to be depredated by Arctic foxes. As geese show a high degree of nest-site fidelity and preferentially occupy nests with better protection against depredation and closer to feeding areas, we propose that Arctic foxes targeted, and were more successful in killing younger, more inexperienced or low-quality geese that occupied less favourable nest sites.
\end{abstract}

\section{Introduction}

The nesting period is a time when both adult birds and their eggs can be particularly vulnerable to depredation (Magnhagen 1991; McLennan et al. 1996). Often, the choice of nesting site can have significant impacts on nesting success rates, with birds predicted to nest where the chances of reproductive success are higher (Fretwell \& Lucus 1969). Nest sites that have higher chances of successful egg hatching may also benefit the adult birds by affording them some protection against depredation (Björklund 1990). Therefore, the choice of nesting site may not always be wholly related to the ability to successfully incubate and hatch eggs, but also linked to improved adult survival. In complex ecosystems, with multiple prey and predator species present, it can be difficult to elucidate the relative importance of nest-site characteristics to adult survival rather than nesting success rates.

As Svalbard has one of the simplest vertebrate tundra food webs in the world (Ims et al. 2013), the archipelago provides an excellent environment in which to study depredation of breeding birds and to investigate if nestsite quality has any effect on adult mortality. The most abundant migratory nesting birds in Svalbard are geese (van der Wal 2005). Geese show nest-site faithfulness and natal philopatry, and during nesting they form loose colonies (Rockwell \& Cooke 1977; Finney \& Cooke 1978; Larsson \& van der Jeugd 1998; Tombre et al. 1998). In Svalbard, during incubation their eggs are susceptible to predation by the Arctic fox (Vulpes lagopus), glaucous gulls (Larus hyperboreus) and the Arctic skua (Stercorarius parasiticus) (Inglis 1977; Eide et al. 2004; Madsen et al. 2007). However, the only predator of adult geese in Svalbard is the Arctic fox (Prestrud 1992).

The most abundant goose species in Svalbard is the pink-footed goose (Anser brachyrhynchus) (Madsen et al. 1999). The population has increased from approximately 10000-15000 individuals in the late 1960s to about 60000-80000 individuals in the last decade (Madsen et al. 2018). Faced with this rapid population increase, Wisz et al. (2008) used species distribution models to predict which landscape features would be important for 
nesting pink-footed geese, allowing areas susceptible to future colonization to be identified. Sites with a southerly aspect, intermediate slopes, at low elevations and with ready access to specific feeding areas were proposed as being preferred for nesting (Wisz et al. 2008). A southerly aspect would ensure earlier snowmelt, allowing nesting geese to start incubation earlier, giving offspring the maximum time available to fledge during the short Arctic summer (Wisz et al. 2008). Intermediate slopes and lower elevations in conjunction with a southerly aspect were thought to promote earlier snowmelt, as well as providing drainage for the nest site (allowing it to remain dry) and giving shelter from cold winds that could increase adult energy loss during incubation (Wisz et al. 2008).

Following from these predictions, a seven-year study of a growing Svalbard pink-footed goose colony assessed if the landscape factors associated with nest sites influenced nesting success rates (Anderson, Madsen, Woodin et al. 2015). Nest sites that had better protection against depredation (those situated on steeper slopes and those with greater visibility from the nest) and that were closer to suitable feeding areas were occupied preferentially during early stages of colony formation, while nest sites occupied later were further away from forage areas and offered poorer protection against depredation (Anderson, Madsen, Woodin et al. 2015). However, despite the preferential selection of particular nest sites, significant differences in nesting success between such sites did not occur (Anderson, Madsen, Woodin et al. 2015). Therefore, the reason for preferential selection of nesting sites with such high-quality characteristics by pink-footed geese remains unexplained.

Rather than being solely based on improved reproductive success, the preferential selection of nest sites with better characteristics may be to reduce the risk of depredation on adult geese by Arctic foxes while the geese are confined to the nest site during incubation. Nest sites that occupy steeper slopes may afford more protection for incubating geese against approaching Arctic foxes than nests on shallower slopes. If the nest site has a greater area of visibility around it, then there may be fewer opportunities for Arctic foxes to approach a nest site undetected and ambush the incubating female goose. Furthermore, if patches of suitable forage vegetation are closer, there may be more opportunities for feeding male pink-footed geese to observe an Arctic fox approaching the nest and to return to it in time to defend it and his mate.

To determine if nest-site characteristics had any effect on adult goose mortality during the nesting period, we studied one of the main pink-footed breeding areas in Svalbard. We predicted that pink-footed goose carcasses found within the colony would be situated closer to nests possessing characteristics less favourable to Arctic fox detection by incubating females (limited visibility from the nest, shallower slopes, further distances from the nest to forage patches). Following on from this, we also predicted that pink-footed goose carcasses found within the colony would be situated closer to unsuccessful nests than to successful ones, as Arctic foxes are more likely to depredate the nest following the killing of one member of the breeding pair. Furthermore, we predicted that depredated geese would be more likely to be associated with nests that had been established more recently, as indicted by a lower fertilization effect around the nest. We also determined if nest proximity to the colony boundary had any relationship with nesting success as it has been suggested, in line with the selfish herd theory, that birds that occupy sites at the colony edge are more likely to suffer egg depredation (Hamilton 1971).

\section{Methods}

Data were collected in 2015 at the Sassendalen pinkfooted goose colony $\left(78^{\circ} 20^{\prime} \mathrm{N} 17^{\circ} \mathrm{E}\right)$, which, as one of the main pink-footed goose breeding areas in Svalbard (Jepsen et al. 2002), has been studied for over a decade. The colony is situated on exposed, vegetated southwest facing tundra slopes and covers an area of approximately $0.76 \mathrm{~km}^{2}$ (Anderson, Madsen, Fuglei et al. 2015). Vegetation is characterized by Cassiope tetragona and Dryas octopetala dwarf shrubs on the slopes (Elvebakk 1997) and fen, marsh and moss tundra where freshwater accumulates (Vanderpuye et al. 2002). The location of pink-footed carcasses, nesting success assessments and nest-site characteristic data were all collected after hatching because the pink-footed goose is particularly shy of humans, with nest losses after human disturbance known to be over one-third (Madsen et al. 2009).

Within the colony, GPS locations of pink-footed goose carcasses were recorded. Carcasses consisted of the body skeleton, particularly the keel, with the meat and feathers stripped away and the feet and heads also absent (Fig. la, b). In some cases, the wings were no longer attached to the rest of the skeleton and were found a short distance away. As we counted more body skeletons than pairs of wings, carcasses that consisted of wings only were excluded as the body of the same individual may already have been accounted for. Although field observations of the killing of breeding pink-footed geese by Arctic foxes indicate that foxes do carry carcasses to the den (J. Madsen pers. obs.), the carcasses included in this study were not found in the immediate vicinity of a fox den. We have therefore assumed that the carcasses had not been transported by the foxes but were attacked and partially 

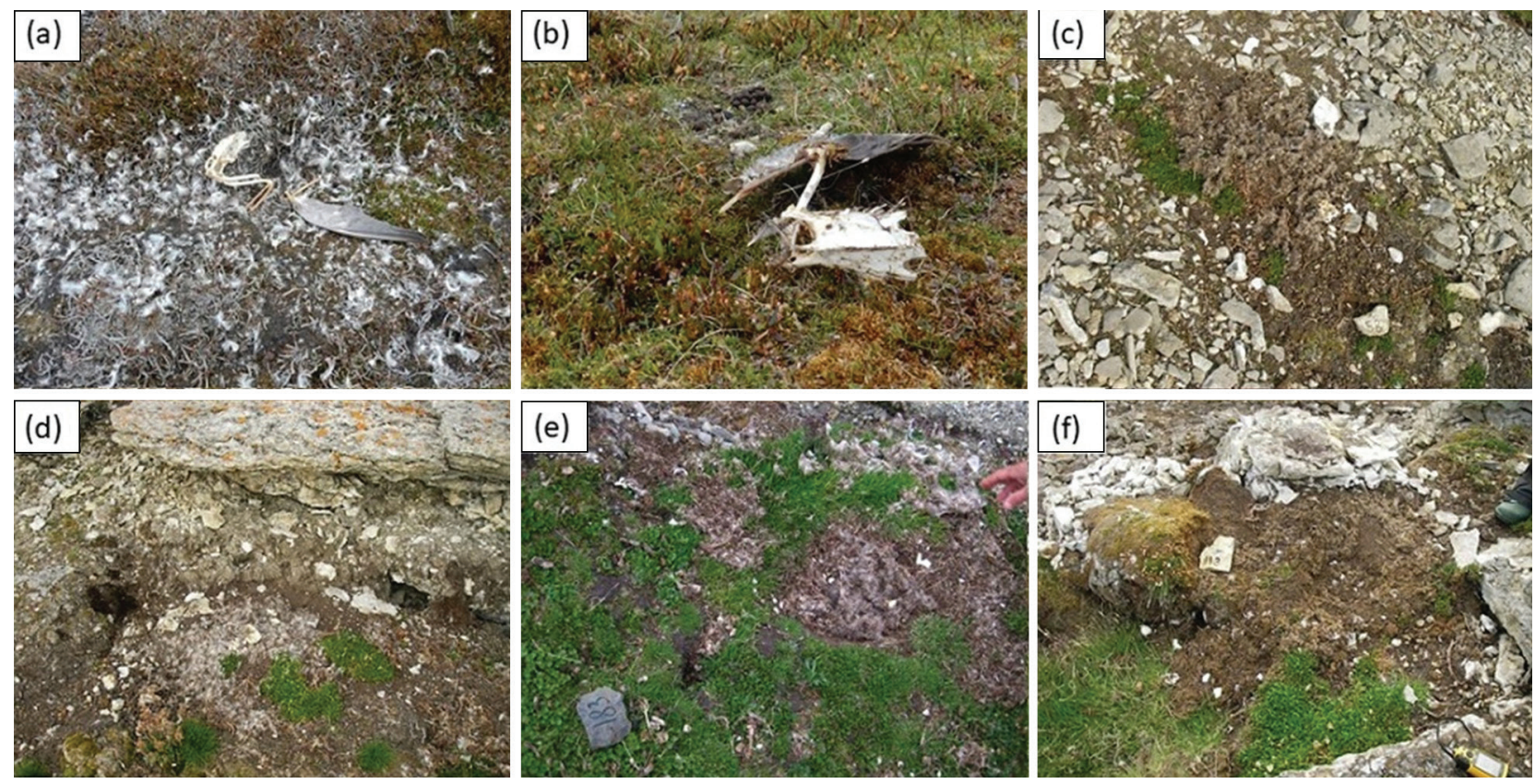

Fig. 1 Pink-footed goose carcasses and nests found within the main pink-footed goose colony in Svalbard. (a-b) Remains of goose carcasses killed by Arctic foxes with plucked feathers clearly visible in (a) and the keel bone visible in (b). (c-d) Examples of the nearest unsuccessful pink-footed goose nests to goose carcasses, showing the sparse vegetation and rocky substrate around the nests. (e-f) Examples of successful pink-footed goose nests, showing the high degree of fertilization of the surrounding vegetation.

eaten where they were killed. Although some moulting or non-breeding geese have been observed in the same valley as the colony studied (although not within the colony), most have been found in other areas of Svalbard (see Goosemap 2012). Therefore, we have assumed that all the carcasses found were breeding geese and not floaters (non-breeders and moulting birds).

To determine pink-footed goose nesting success, methodical searches for nests were undertaken. A systematic protocol was followed and searches were conducted by two trained observers over the same fixed area to ensure consistency in spatial coverage (see Anderson, Madsen, Fuglei et al. 2015 for more details). Nests had been used during the current breeding season if fresh down feathers were found within the nest bowl and fresh droppings were present in the nest vicinity. Empty nests and nests containing eggshells with no membranes were recorded as having been depredated. Successful nests were those where membranes were still present within the eggshell remains (Davis et al. 1998; Madsen et al. 2007; Prop et al. 2013). A nest was considered to have been successful if at least one egg hatched.

Nest-site characteristics that were considered as potentially important for adult survival were (1) visibility from the nest, (2) slope of the ground underlying the nest site and (3) distance to visible forage vegetation. Slope was estimated in the field with a home-made clinometer (Andrews 1988) and measured to the nearest $5^{\circ}$. The distance to visible forage vegetation and visibility from the nest were measured using a range finder (Nikon Forestry $550,10-500 \mathrm{~m}$ ) to the nearest $1.0 \mathrm{~m}$ for distances $\geq 100 \mathrm{~m}$ and $0.2 \mathrm{~m}$ for distances $<100 \mathrm{~m}$, or by eye for distances less than $10 \mathrm{~m}$ (to the nearest $0.2 \mathrm{~m}$ approximately). In the case of visibility from the nest, distances were measured in the four cardinal directions from the nest to the nearest visual obstruction (e.g., boulders, rocky outcrops). A single figure indicating the area of visibility around the nest was calculated using the area of an ellipse (area $=\pi \times A \times B$, where $\pi$ equals $3.14, A$ equals half the major axis and $B$ equals half the minor axis), centred on the nest.

In addition, we estimated the fertilization effect (to $5 \%$ ) of accumulated goose droppings at the nest site as this could indicate if a nest was newly established or had been in use for a number of years (higher fertilization indicative of longer use by virtue of years of accumulated goose droppings). On account of nest-site faithfulness and natal-site philopatry exhibited by geese (Rockwell $\delta$ Cooke 1977; Finney \& Cooke 1978; Larsson \& van der Jeugd 1998; Tombre et al. 1998), we expected sites with a greater degree of fertilization to have been occupied by older birds whose experience reduced their risk of depredation by Arctic foxes. 
The proximity tool in ArcGIS was used to generate the distance of each carcass to the nearest nest and the distances of successful and unsuccessful nests to the colony boundary. A chi-squared test was used to determine if goose carcasses were located closer to unsuccessful nests than would be expected by chance. We used a binomial logistic regression model with a logit link to analyse the relationships between survival of adult nesting geese and (1) visibility from nest site, (2) slope, (3) distance to nearest visible forage patch, (4) fertilization effect at the nest site and (5) distance to colony boundary. All spatial analyses were carried out in ArcGIS (version 10.5 copyright 1999-2016 Esri Inc.) and statistical analyses in the $\mathrm{R}$ programme, version 3.5.1 (R Core Team 2017). Statistical significance was determined at the $0.05 \alpha$-level.

\section{Results}

Thirty-three adult goose carcasses (Fig. la, b) were found within the colony in 2015 . As 125 (49\%) of the nests found were unsuccessful, the number of carcasses accounted for, at most, one bird from just over a quarter $(26 \%)$ of the pairs of geese from unsuccessful nests. Furthermore, the nearest nest to a goose carcass was almost always unsuccessful (32 unsuccessful nests compared with 1 successful nest, $\chi_{1}^{2}=32.2, p<0.001$; Fig. 1c, d). Goose carcasses were found, on average, $9.96 \mathrm{~m}$ (range: 0-35.3 m) away from the nearest nest.

A higher probability of adult mortality was significantly associated with nest sites that had limited visibility from the nest $(z=4.01, p<0.001$; Fig. 2a), where the underlying slope was shallower $(z=2.29, p=0.02$; Fig. $2 b)$ and where the fertilization effect at the nest site was low $(z=2.97, p=0.003$; Fig. $2 \mathrm{~d})$. The distance to suitable forage patches was only important to adult survival at the $\alpha=0.1$ level, with a higher probability of adult mortality associated with nest sites that were further away from forage areas $(z=1.69, p=0.09$; Fig. $2 \mathrm{c})$. The average distance of unsuccessful nests to the colony boundary (188 m; range: $27-308 \mathrm{~m}$ ) was only marginally greater than that of successful nests (137 m; range: 46-262 m). There was no evidence to support the view that increased adult goose mortality was associated with nests closer to the colony boundary $(z=1.58, p=0.1)$.

\section{Discussion}

The characteristics of a nest site are thought to play an important part in the nesting success of many colonyforming birds that nest in heterogeneous environments, with individuals preferentially selecting sites where their reproductive success is increased (Fretwell \& Lucas 1969). Although Anderson and co-workers found that within the pink-footed colony studied here, nest sites with greater visibility, situated on steeper slopes and closer to patches of forage vegetation visible from the nest were preferentially occupied (Anderson, Madsen, Fuglei et al. 2015; Anderson, Madsen, Woodin et al. 2015, they also found that there was no evidence of improved nesting success for birds that occupied such sites (Anderson, Madsen, Woodin et al. 2015). An alternative hypothesis for the preferential selection of such nest sites, which we have explored here, is that they provide greater protection against adult goose depredation during the incubation period.

Our findings here are based on the pink-footed goose carcasses found in just over a quarter of the unsuccessful nests recorded in the colony. We hypothesize that we did not find more carcasses because the geese associated with those nests either escaped from attacking Arctic foxes or were simply absent from the nest site when it was depredated because they were foraging or had abandoned the nest. The nest sites closest to the goose carcasses found in this colony had limited visibility and were situated
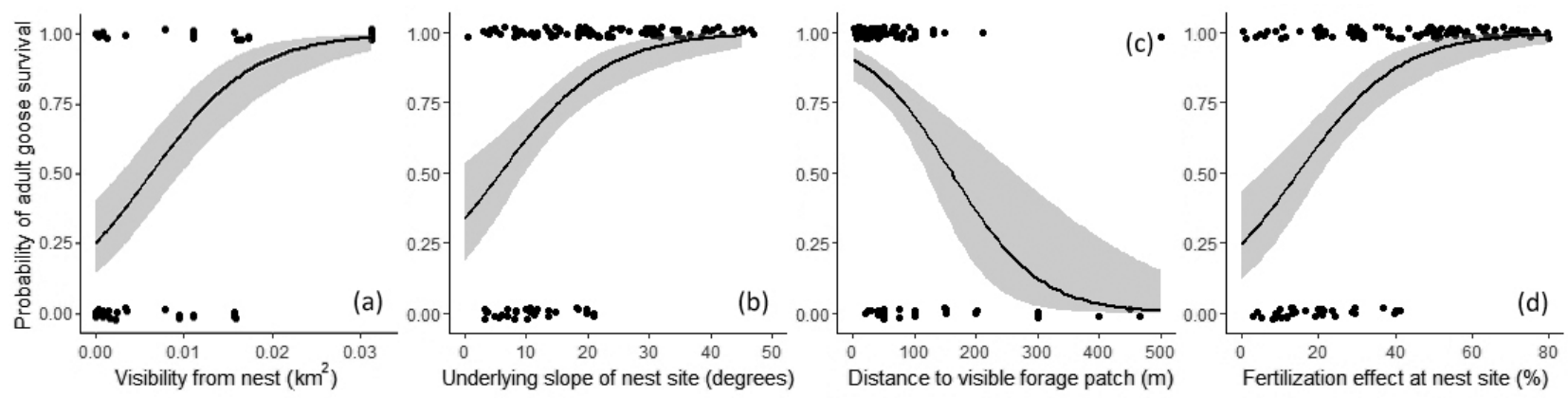

Fig. 2 Relationship between probability of adult goose survival and (a) visibility from the nest site, (b) underlying slope of the nest site, (c) distance to patch of suitable forage visible from the nest and (d) fertilization effect at the nest site. Survival probabilities are displayed from 0 (death) to 1 (survival), with the grey shaded areas indicating the $95 \%$ confidence intervals, and jittered values to overcome overlapping of data points. 
on flatter underlying slopes. By comparison, at a nearby pink-footed goose colony (about $0.6 \mathrm{~km}$ distant), where all nest sites are situated on steep cliffs with good visibility, we have failed to find any pink-footed goose carcasses in over 10 years of study despite the presence of active Arctic fox dens in the vicinity (see Anderson, Madsen, Fuglei et al. 2015). We therefore hypothesize that adult geese occupying such poorer quality nest sites have a greater probability of being killed.

Birds that occupy the less preferred nest sites may be young and inexperienced, thereby lacking the knowledge needed to locate, select and secure the better protected sites. By virtue of their nesting inexperience, young birds may also be less aware of how to deal with attacks by Arctic foxes (see Fig. 3). Alternatively, less favourable nest sites may have been occupied by low-quality geese, which may also be more vulnerable to depredation. We found no evidence to suggest that birds occupying nest sites at the periphery of the colony experienced higher mortality rates — the selfish herd theory (Hamilton 1971). We speculate that in pink-footed goose colonies it is the nest sites situated on shallower slopes, with limited visibility, that are occupied by the more inexperienced adults. Indeed, the low fertilization levels found at the sites of the unsuccessful nests associated with dead adult geese seem to lend support to the theory that these nests were less well established and therefore likely occupied by younger birds, particularly because geese exhibit nestsite philopatry (Cooch et al. 1993; Fowler et al. 2004).

Body condition of the adult geese may also have affected their depredation risk. For instance, when snowmelt is late spring feeding opportunities are reduced (Anderson et al. 2012), potentially leading to lower fat reserves (Madsen et al. 2007). Under such conditions nesting females are predicted to be under increased predation risk by Arctic foxes (only the female undertakes incubation) if the male leaves the nest site to forage (Madsen et al. 2007). If a young and/or inexperienced male leaves his mate to feed (Løvenskiold 1964; Nyholm 1965; Inglis 1977), this could increase the chances of the female being killed by an Arctic fox as a single goose is much less able to defend itself and its nest against an Arctic fox than a pair of geese (Inglis 1977; Frafjord 1990; see Fig. 3). As this study was undertaken during a relatively late snowmelt year (average May temperatures were $-2.2^{\circ} \mathrm{C}$, data from Longyearbyen Airport, approximately $37 \mathrm{~km}$ west of the study area; available from Norwegian Meteorological Institute), we cannot rule out the impact that body condition may have had on adult depredation risk. We cannot verify if the goose carcasses found were male or female, but the close proximity of the carcasses to unsuccessful nests led us to suspect that they were female birds that had remained on the nest when the male had left to feed. Under climatic conditions allowing birds to feed to maintain adequate fat reserves, we might expect adult goose mortality to be lower as there would presumably be fewer occasions when the male had departed from the nest site to feed. However, as we found only a weak association between increased adult mortality and nest sites that were further away from forage patches, it may be that nest defensibility against Arctic foxes is a more important factor in adult mortality than proximity to feeding areas. Furthermore, we may have overlooked forage patches that we deemed too small for foraging (less than $1 \mathrm{~m} \times 1 \mathrm{~m}$ ) and we only considered forage patches in wetter areas that had large amounts of Dupontia species and Eriophorum scheuchzerispecies that pink-footed geese are known to show a preference for (Anderson et al. 2012). As pink-footed geese are also known to feed on other plant species,
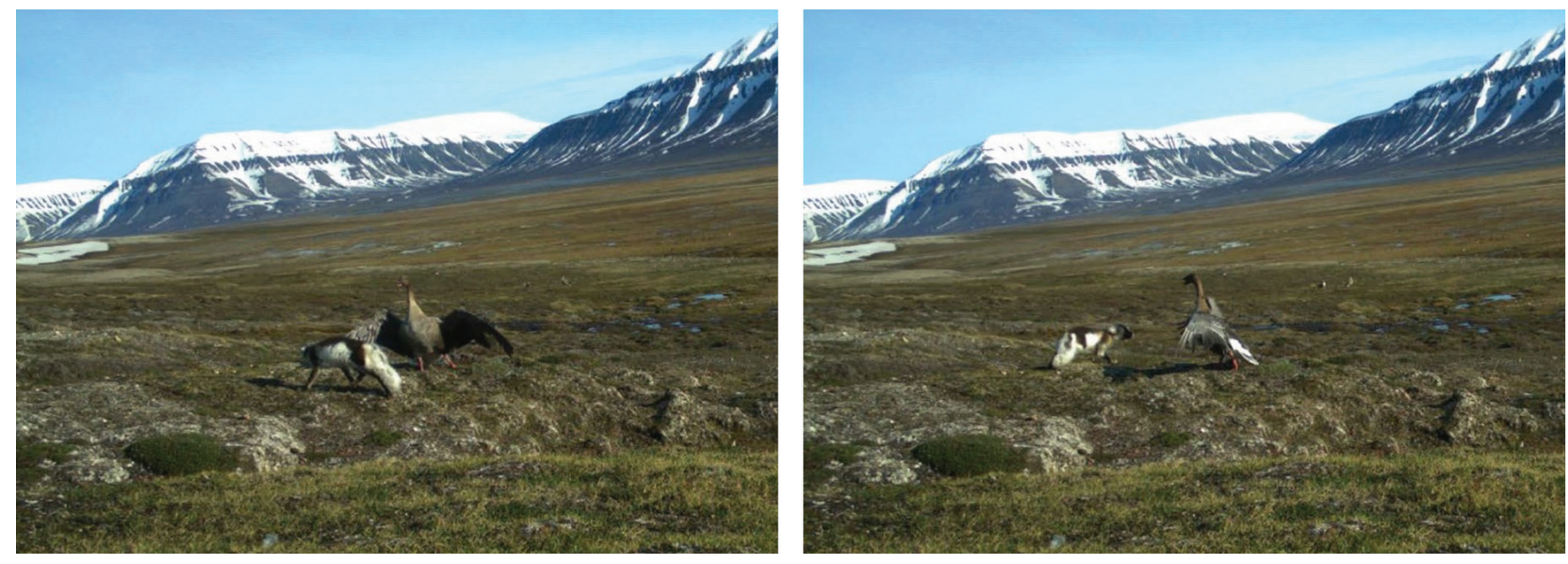

Fig. 3 A solitary adult female pink-footed goose attempting to defend the nest and herself against attack by an Arctic fox (images provided by J. Madsen). 
particularly Bistorta vivipara in drier areas (Anderson et al. 2012), we may have discounted other areas of vegetation that could be utilized if needed. Of course, the effects of adult body condition, mediated by spring weather conditions, and the age or experience of birds may both contribute to their depredation. For instance, during later snowmelt years, younger or inexperienced birds may be in poorer condition because older, more dominant birds have restricted their access to preferential nest sites and feeding opportunities. Dominant barnacle geese (Branta leucopsis) have been shown to feed for longer than shy individuals (Kurvers et al. 2009).

We suspect that Arctic foxes in this area have intimate knowledge of their territory and have developed an accurate spatial map of the nests present (Careau et al. 2008). This is particularly likely because one of the Arctic fox dens in the area is located within the colony and this species is well known for its egg-catching ability (Careau et al. 2008) and propensity to use goslings and adult geese as an immediate food source for both adult foxes and their pups during the short Arctic summer (Eide et al. 2005). Arctic foxes are therefore likely to be well aware of which nests may be easier to depredate because of factors such as limited visibility, which would allow a fox to approach a nest without being seen by adult geese.

Although this study has added to our knowledge of the linkages between nest-site choice and adult survival, a number of aspects remain unknown and warrant further investigation. For instance, despite evidence showing that it is the female goose that chooses a nest site (Avise et al. 1992; Fowler et al. 2004), we are unable to determine if it is the female that succumbs to depredation because of her choice of a poor-quality nest site. Even though the carcasses we found were very close to nest sites, the dead birds may have been males that were attacked while absent from the nest feeding. To fully elucidate the relationship between adult goose mortality, nest-site characteristics and body condition, further studies under a range of different spring snow conditions would be required. The use of camera traps, which have been successfully employed in similar studies elsewhere, could further enhance our understanding of these predator-prey relationships.

\section{Acknowledgements}

We thank Norwegian Polar Institute for logistical support and the Governor of Svalbard for allowing access to Sassendalen. The authors thank the Climate-ecological Observatory for Arctic Tundra programme for assistance with this study. Comments and suggestions from reviewers greatly improved the manuscript, and we thank them for their time and recommendations.

\section{Disclosure statement}

No potential conflict of interest was reported by the authors.

\section{References}

Anderson H.B., Godfrey T.G., Woodin S.J. \& van der Wal R. 2012. Finding food in a highly seasonal landscape: where and how pink-footed geese Anser brachyrhynchus forage during the Arctic spring. Journal of Avian Biology 43, 415-422, http://dx.doi.org/10.1111/j.1600-048X.2012.05699.x.

Anderson H.B., Madsen J., Fuglei E., Jensen G.H., Woodin S.J. \& van der Wal R. 2015. The dilemma of where to nest: influence of spring snow cover, food proximity and predator abundance on reproductive success of an Arctic-breeding migratory herbivore is dependent on nesting habitat choice. Polar Biology 38, 153-162, http://dx.doi. org/10.1007/s00300-014-1574-y.

Anderson H.B., Madsen J., Woodin S.J. \& van der Wal R. 2015. Where to settle in a rapidly expanding bird colony: a case study on colony expansion in High Arctic breeding geese. Behavoral Ecology and Sociobiology 69, 325-334, http://dx.doi.org/10.1007/s00265-014-1845-1.

Andrews P. 1988. Estimating slope for predicting fire behavior. Fire Management Notes 49, 16-18.

Avise J.C., Alisauskas R.T., Nelson W.S. \& Ankney C.D. 1992. Matriarchal population genetic structure in an avian species with female natal philopatry. Evolution 46, 1084-1096, http://dx.doi.org/10.1111/j.1558-5646.1992.tb00621.x.

Björklund M. 1990. Nest failures in the scarlet rose finch Carpodacus erythrinus. Ibis 132, 613-617, http://dx.doi. org/10.1111/j.1474-919X.1990.tb00286.X.

Careau V., Lecomte N., Bêty J., Giroux J.-F., Gauthier G. \& Berteaux D. 2008. Hoarding of pulsed resources: temporal variations in egg-caching by Arctic fox. Ecoscience 15, 268-276, http://dx.doi.org/10.2980/15-2-3097.

Cooch E.G., Jeffries R.L., Rockwell R.F. \& Cooke F. 1993. Environmental change and the cost of philopatry: an example in the lesser snow goose. Oecologia 93, 128-138, http://dx.doi.org/10.1007/BF00321202.

Davis J.B., Kaminski R.M. \& Stephens S.E. 1998. Wood duck eggshell membranes predict duckling numbers. Wildlife Society Bulletin 26, 299-301.

Eide N.E., Eid P.M., Prestrud P. \& Swenson J.E. 2005. Dietary responses of Arctic foxes Alopex lagopus to changing prey across an Arctic landscape. Wildlife Biology 11, 109-121, http://dx.doi. org/10.2981/0909-6396(2005) 1 1 [109:DROAFA]2.0.CO;2.

Eide N.E., Jepsen J.U. \& Prestrud P. 2004. Spatial organization of reproductive Arctic foxes Alopex lagopus: responses to changes in spatial and temporal availability of prey. Journal of Animal Ecology 73, 1056-1068, http://dx.doi. org/10.1111/j.0021-8790.2004.00885.x.

Elvebakk A. 1997. Tundra diversity and ecological characteristics of Svalbard. In F.E. Wielgolaski (ed.): Ecosystems of the world. Vol. 3. Polar and alpine tundra. Pp. 347-359. Amsterdam: Elsevier. 
Finney G. \& Cooke F. 1978. Reproductive habits in snow goose-influence of female age. Condor 80, 147-158, http://dx.doi.org/10.2307/1367914.

Fowler A.C., Eadie J.M. \& Ely C.R. 2004. Relatedness and nesting dispersion within breeding populations of greater white-fronted geese. Condor 106, 600-607, http://dx.doi. org/10.1650/7446.

Frafjord K. 1990. A study of the pink-footed goose in Gipsdalen, Svalbard, during the pre-breeding and early breeding periods. In T. Severinsen \& R. Hansson (eds.): Environmental atlas Gipsdalen, Svalbard. Vol. 3. Reports on the fauna of Gipsdalen. Norwegian Polar Institute Report 66. Pp. 1-18. Oslo: Norwegian Polar Research Institute.

Fretwell S.D. \& Lucas H.L. 1969. On territorial behaviour and other factors influencing habitat distribution in birds. Part 1. Theoretical development. Acta Biotheoretica 1,16-36.

Goosemap 2012. Maps. Pink-footed goose. Moulting, non-breeding (two maps). Accessed on the internet at https://goosemap.nina.no/goosemap_eng/Maps-and-data/Maps on 27 February 2019.

Hamilton W.D. 1971. Geometry for the selfish herd. Journal of Theoretical Biology 31, 295-311, http://dx.doi.org/10.1016/ 0022-5193(71)90189-5.

Ims R.A., Jepsen J.U., Stien A. \& Yoccoz N.G. 2013. Science plan for COAT: Climate-ecological Observatory for Arctic Tundra. Fram Centre Report Series 1. Tromsø: Fram Centre.

Inglis I.R. 1977. The breeding behaviour of the pink-footed goose: behavioural correlates of nesting success. Animal Behaviour 25, 747-764, http://dx.doi.org/10.1016/0003(77) $90125-7$.

Jepsen J.U., Eide N.E., Prestrud P. \& Jacobsen L.B. 2002. The importance of prey distribution in habitat use by Arctic foxes (Alopex lagopus). Canadian Journal of Zoology 80, 418-429, http://dx.doi.org/10.1139/Z02-023.

Kurvers R.H.J.M., Prins H.H.T., van Wieren S.E., van Oers K., Nolet B.A. \& Ydenberg R.C. 2009. The effect of personality on social foraging: shy barnacle geese scrounge more. Proceedings of the Royal Society B 277, 601-608, http://dx.doi. org/10.1098/rspb.2009.1474.

Larsson K. \& van der Jeugd H.P. 1998. Continuing growth of the Baltic barnacle goose population: number of individuals and reproductive success in different colonies. In F. Mehlum et al. (eds.): Research on Arctic geese. Norsk Polarinstitutt Skrifter 200. Pp. 213-219. Oslo: Norwegian Polar Institute.

Løvenskiold H.L. 1964. No. 23. Anser fabalis brachyrhynchus. In H.L. Løvenskiold: Avifauna Svalbardensis. Norsk Polarinstitutt Skrifter 129. Pp. 125-134. Oslo: Norwegian Polar Institute.

Madsen J., Jensen G.H., Cottaar F., Amstrup O., Bak M., Bakken J., Balsby T.T.J., Christensen T.K., Clausen K.K., Frikke J., Gundersen O.M., Kjeldsen J.P., Koffijberg K., Kuijken E., Månsson J., Nicolaisen P.I., Nielsen H.H., Nilsson L., Reinsborg T., Ødegaard P.I., Pessa J., Shimmings P., Tombre I. \& Verschuere C. 2018. Svalbard pink-footed goose. Population status report 2017-2018. Doc. AEWA/EGMIWG/3.8. Leeuwarden, The Netherlands: AWEA European Goose Management International Working Group.

Madsen J., Kuijken E., Meire P., Cottaar F., Haitjema T., Nicolaisen P.I., Bønes T. \& Mehlum F. 1999. Pink-footed goose Anser brachyrhynchus: Svalbard. In J. Madsen et al. (eds.): Goose populations of the western Palearctic. A review of status and distribution. Pp. 82-93. Wageningen, The Netherlands: Wetlands International.

Madsen J., Tamstorf M., Klaassen M., Eide N., Glahder C., Rigét F., Nyegaard H. \& Cottaar F. 2007. Effects of snow cover on the timing and success of reproduction in High-Arctic pink-footed geese Anser brachyrhynchus. Polar Biology 30, 1363-1372, http://dx.doi.org/10.1007/ s00300-007-0296-9.

Madsen J., Tombre I. \& Eide N.E. 2009. Effects of disturbance on geese in Svalbard: implications for regulating increasing tourism. Polar Research 28, 376-389, http://dx.doi. org/10.1111/j.1751-8369.2009.00120.x.

Magnhagen C. 1991. Predation risk as a cost of reproduction. Trend in Ecology and Evolution 6, 183-186, http://dx.doi. org/10.1016/0169-5347(91)90210-O.

McLennan J.A., Potter M.A., Robertson H.A., Wake G.C., Colbourne R., Dew L., Joyce L., McCann A.J., Miles J., Miller P.J. \& Reid J. 1996. Role of predation in the decline of kiwi, Apteryx spp., in New Zealand. New Zealand Journal of Ecology 20, 27-35.

Nyholm E.S. 1965. Ecological observations on the geese of Spitsbergen. Annales Zoologica Fennici 2, 197-207.

Prestrud P. 1992. Food habitats and observations of the hunting behaviour of Arctic foxes, Alopex lagopus, in Svalbard. Canadian Field Naturalist 106, 225-236.

Prop J., Oudman T., van Spanje T.M. \& Wolters E.H. 2013. Patterns of predation of pink-footed goose nests by polar bear. Ornis Norvegica 36,38-46, http://dx.doi.org/10.15845/ on.v36i0.439

$\mathrm{R}$ Core Team 2017. R: A language and environment for statistical computing. Vienna: R Foundation for Statistical Computing.

Rockwell R.F. \& Cooke F. 1977. Gene flow and local adaptation in a colonially nesting dimorphic birdthe lesser snow goose (Anser caerulescens caerulescens). American Naturalist 111, 91-97, http://dx.doi. org/10.1086/283140.

Tombre I.M., Mehlum F. \& Loonen M.J.J.E. 1998. The Kongsfjorden colony of barnacle geese: nest distribution and the use of breeding islands 1980-1997. In F. Mehlum et al. (eds.): Research on Arctic geese. Norsk Polarinstitutt Skrifter 200. Pp. 57-65. Oslo: Norwegian Polar Institute.

Vanderpuye A.W., Elvebakk A. \& Nilsen L. 2002. Plant communities along environmental gradients of High-Arctic mires in Sassendalen, Svalbard. Journal of Vegetation Science 13, 875-884, http://dx.doi.org/10.1111/j.1654-1103.2002. tb02117.x.

Van der Wal R. 2005. Plant-animal interactions. In M. Nuttall (ed.): Encyclopaedia of the Arctic. Vol. 3. Pp. 1649-1650. New York: Routledge.

Wisz M.S., Tamstorf M.P., Madsen J. \& Jespersen M. 2008. Where might the western Svalbard tundra by vulnerable to pink-footed goose (Anser brachyrhynchus) population expansion? Clues from species distribution models. Diversity and Distributions 14, 26-37, http://dx.doi.org/ $10.1111 /$ j.1472-4642.2007.00408.x. 